\title{
Challenges to Replication and Iteration in Field Experiments: Evidence from two Direct Mail Shots
}

\section{Online Appendix}

\author{
By Jake Bowers, Nathaniel Higgins, Dean Karlan, Sarah Tulman, And Jonathan \\ ZINMAN
}

TABLE 1 - REGRESSION RESULTS

\begin{tabular}{lcc}
\hline \hline $\begin{array}{l}\text { Dependent variable }=1 \text { if Borrowed under } \\
\text { program }\end{array}$ & Experiment $1^{\text {a }}$ & Experiment 2 \\
\hline Direct effect of mailer & $0.00056404^{* * *}$ & -0.00006748 \\
& $(0.000167)$ & $(0.0001183)$ \\
No mailer in mailer county (spillover effect) & -- & -0.0001437 \\
& & $(0.0001184)$ \\
Constant & $2.21 \mathrm{E}-16^{* * *}$ & $0.001323^{* *}$ \\
& $(5.39 \mathrm{E}-17)$ & $(0.0001699)$ \\
& $\mathrm{N}=288,905$ & $\mathrm{~N}=515,048$ \\
\hline
\end{tabular}

Notes: Unit of observation is the individual in Column 1, and the household (potentially multiple female farmers residing at the same address) in Column 2. Each column presents results from a single OLS regression on the treatnemt variable(s) — based on random assignment of getting a direct mailer-and randomization strata. The 2015 sample frame is the US Census of Agriculture in Alabama, Arkansas, Georgia, Kentucky, Louisiana, Mississippi, North Carolina, South Carolina, and Tennessee. The 2015 experiment was randomized at the zip-code level, stratified by using a block randomization on number and density of farmers. Specifically, using the 2012 Census of Agriculture, we calculated the deciles of the estimated number and density (as a proportion of all farmers) of likely eligible farmers by zip code within each state, with likely eligible farmers being defined as those targeted by the Microloan program (minorities, women, beginning farmers, etc.). We dropped zip codes with less than 1 targeted farmer, and zip codes such that more than $80 \%$ of farmers were non-targeted farmers. We then combined these deciles, creating one hundred blocks, and then within each block assigned, $50 \%$ of zip codes to treatment and 50\% to control. Standard errors in Experiment 1 are clustered at the zip code level. For Experiment 2 we constructed pairs of potential-to-treat counties (rather than zip codes) and pure-control counties based on the number of farmers within each county, prioritizing the best matches between counties that were feasible given the constraints on the number of letters we could send out. We identified adjacent counties and removed them from consideration of paired counties for sampling. This was done to improve the likelihood that the farmers in pure control counties were not in contact with any farmers that received the marketing. We then ordered counties by number of eligible farmers, to create pairs of counties, and then randomly assigned one from each pair to treatment and one to control. Within treatment counties, we then randomly assigned $50 \%$ of female farmers to receive a marketing letter, and $50 \%$ to not.

\footnotetext{
*** Significant at the 1 percent level.

** Significant at the 5 percent level.

* Significant at the 10 percent level.
} 


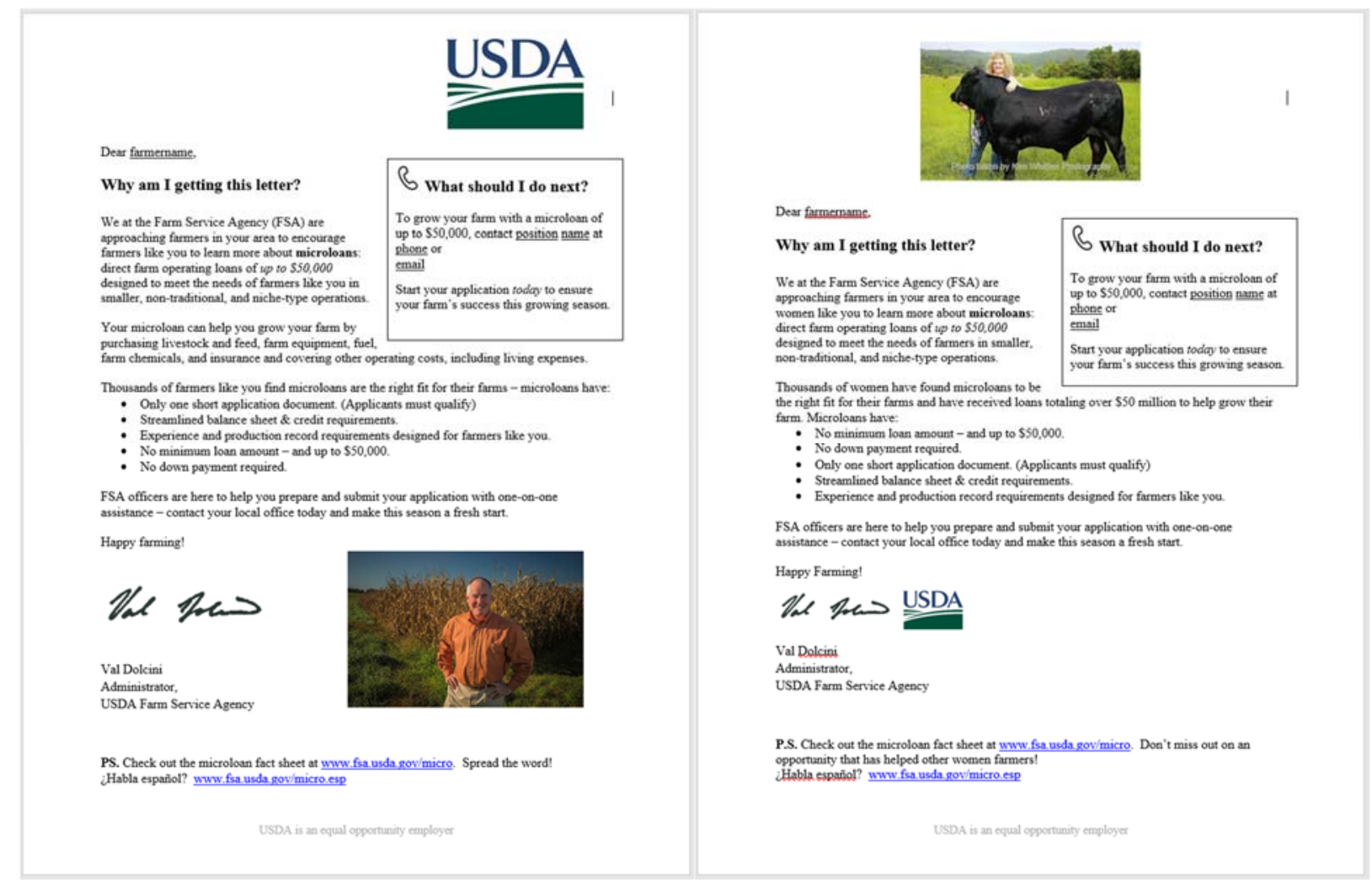

FIGURE 1. LETTERS FOR BOTH EXPERIMENTS

Note: FSA mailed the left-side (right-side) letter to randomly assigned farmers in Experiment 1 (2). 